\title{
Médiévales
}

Langues, Textes, Histoire

57 | automne 2009

Langages politiques, $\mathrm{XII}{ }^{\mathrm{e}}-\mathrm{XV}^{\mathrm{e}}$ siècle

\section{Denis LÉVY WILLARD, Le Livre dans la société juive médiévale de la France du Nord, Paris, Éditions du Cerf (Nouvelle Gallia Judaica, 3), 2008, 213 p.}

\section{Danièle Sansy}

\section{(2) OpenEdition}

\section{Journals}

Édition électronique

URL : https://journals.openedition.org/medievales/5826

DOI : $10.4000 /$ medievales. 5826

ISSN : 1777-5892

Éditeur

Presses universitaires de Vincennes

\section{Édition imprimée}

Date de publication : 20 décembre 2009

Pagination : $170-172$

ISBN : 978-2-84292-241-2

ISSN : 0751-2708

Référence électronique

Danièle Sansy, "Denis Lévy WilLARD, Le Livre dans la société juive médiévale de la France du Nord, Paris, Éditions du Cerf (Nouvelle Gallia Judaica, 3), 2008, 213 p. ». Médiévales [En ligne], 57 | automne 2009, mis en ligne le 22 mars 2010, consulté le 22 avril 2022. URL : http://journals.openedition.org/ medievales/5826 ; DOI : https://doi.org/10.4000/medievales.5826 
drier traditionnel des termes de paiement. L'emprisonnement pour dette était marqué par sa courte durée (la moitié des prisonniers restaient moins de 48 heures et les trois quarts une semaine et moins) qui était pourtant supérieure à la durée moyenne d'emprisonnement pour les autres délits. Ces prisonniers ne semblent pas avoir bénéficié d'un traitement de faveur particulier. On se contentait de les distinguer des prisonniers criminels et le traitement qui leur était appliqué dépendait étroitement de leur état social, comme pour le reste des délits. Seuls les prisonniers les plus pauvres étaient enfermés aux frais des créanciers. La mise en regard du coût moyen que représentait l'ensemble des frais d'incarcération et des sommes à recouvrer permet de conclure que la procédure était rentable pour les créanciers. En revanche, si elle exposait le débiteur à la honte, elle n'épargnait pas l'image du créancier qui pouvait en retirer une réputation d'usurier, la perte d'honneur était cependant moins redoutée par les débiteurs que le séjour en prison lui-même. Le débiteur se démenait donc pour sortir au plus vite selon des modalités que la documentation ne nous permet de connaître que lorsque la libération faisait l'objet d'une procédure judiciaire. La sortie pouvait être mise en œuvre parce que le débiteur avait prouvé que le créancier n'avait pas le droit de saisir son corps ou bien au terme d'une négociation entre les deux parties, d'une cession de biens du débiteur ou encore en faisant usage d'une lettre royale de répit. La voie la plus courante était celle de la négociation qui aboutissait à un échelonnement du paiement de la dette qui pouvait être accompagné d'une véritable libération au seulement d'un élargissement, un passage dans le système de la prison « ouverte », jusqu'au règlement total de la dette.

$\mathrm{Au}$ terme de cette passionnante étude, on peut finalement se satisfaire que la focalisation des historiens et des juristes sur la seule doctrine juridique au détriment des pratiques judiciaires ait eu pour conséquence de laisser si longtemps dans l'ombre la question de la prison pour dette. Cela a permis à Julie Claustre de construire son objet d'étude à la croisée de l'histoire du droit et d'une histoire économique qui s'est récemment profondément renouvelée pour finalement nous livrer un travail admirable aussi bien du point de vue de la méthode qu'en termes de maturité de réflexion.

Valérie THEIS

Denis Lévy Willard, Le Livre dans la société juive médiévale de la France du Nord, Paris, Éditions du Cerf (Nouvelle Gallia Judaica, 3), 2008, 213 p.

Le titre ne reflète qu'imparfaitement l'importance de cette étude qui, loin d'être limitée au nord de la France, embrasse l'aire ashkénaze (France du Nord et Allemagne, mais sans aborder l'Angleterre) et abonde d'exemples issus du monde sépharade (Provence, Péninsule ibérique) et d'Italie, voire de la Méditerranée orientale (Genizah du Caire notamment). Malgré l'estimation élevée de témoins conservés dans les bibliothèques actuelles (plusieurs dizaines de milliers de manuscrits ou fragments de manuscrits ont survécu aux destructions naturelles, aux confiscations et aux persécutions), les codex ne livrent dans les colophons ou les pages de garde que des données fragmentaires sur le scribe et le lieu de la copie, le nom d'un possesseur ou les conditions d'un achat, et ne peuvent suffire à retracer l'histoire du livre hébreu entre le $\mathrm{XI}^{\mathrm{e}}$ et le $\mathrm{XV}^{\mathrm{e}}$ siècle. C'est donc à travers les textes eux-mêmes que D. Lévy Willard s'est livré à une enquête minutieuse quant aux usages de ces livres, leurs auteurs, leur commercialisation, leur prêt ou leur location, enfin leur disparition éventuelle : les informations tirées des commentaires bibliques et de la littérature talmudique ont été enrichies par le dépouillement des responsa des principaux décisionnaires, tel Meïr de Rothenbourg (vers 1212-1293), et ce malgré les limites du genre (p. 14-16). 
D. Lévy-Willard a réservé en appendice la présentation des principaux auteurs étudiés et de leurs œuvres (p. 177-189).

Ce n'est que tardivement par rapport au monde chrétien que le codex est entré en usage dans les communautés juives, longtemps attachées exclusivement au rouleau, support du livre sacré par excellence, le Sefer Torah, et qui est resté aussi celui, privilégié, du livre d'Esther. Mentionnés dès le $\mathrm{IX}^{\mathrm{e}}$ siècle en Orient, les premiers codex hébreux ont été fabriqués en Europe à partir du $\mathrm{XI}^{\mathrm{e}}$ siècle (Italie) et du $\mathrm{XII}^{\mathrm{e}}$ siècle (France, Allemagne et Espagne) et leur production a augmenté jusqu'au $\mathrm{XV}^{\mathrm{e}}$ siècle, pendant lequel a été produite la moitié des manuscrits aujourd'hui connus, jusqu'à l'apparition des premiers livres imprimés. La fabrication du livre hébreu est envisagée, au-delà des aspects matériels (supports, encre, ponctuation, mise en page et décoration) déjà bien étudiés par Colette Sirat, Malachi Beit-Arié ou Bezalel Narkiss ${ }^{5}$, dans toute sa dimension socio-économique : contrairement au mode de production développé en milieu chrétien, les livres hébreux ne sont généralement pas fabriqués dans des ateliers, mais sont réalisés à la commande. Le travail valorisé des scribes (p. 80-121), professionnels ou occasionnels, qui furent exceptionnellement des femmes, est vraisemblablement une activité individuelle, les scribes copiant le plus souvent pour leur usage personnel. D. Lévy Willard confirme que, contrairement à l'idée répandue selon laquelle l'interdit des représentations figurées aurait amené les juifs à confier l'illustration de leurs livres à des artistes chrétiens, nombreux sont les juifs ayant contribué à la décoration des manuscrits hébraïques, sous forme de dessins zoomorphes ou de micrographies, les scribes étant parfois capables de réaliser euxmêmes la décoration.

Auteur, rédacteur, copiste... : esquisser leurs figures permet à D. Lévy Willard de proposer une typologie des textes composés et lus dans la société juive. Si la littérature religieuse, en particulier la Bible et le Talmud et leurs commentaires, les rituels de prières ou les livres de préceptes occupent dans toutes les communautés une place prépondérante, la traduction d'œuvres contemporaines en hébreu ou la rédaction d'œuvres historiques sont restées marginales. D. Lévy Willard rappelle la méfiance des communautés ashkénazes à l'égard de la littérature profane, alors que les communautés de l'Europe méditerranéenne ont toujours accordé beaucoup d'importance aux écrits philosophiques et scientifiques. De fait, les livres ont circulé en milieu juif, car ils étaient destinés avant tout à la prière et à l'étude. Celle-ci, particulièrement valorisée dans la société juive, est instituée en véritable obligation religieuse pour chaque homme : contrairement au milieu chrétien environnant, l'accès à l'éducation est généralisé au sein des communautés, dans tous les milieux sociaux et, dans une moindre mesure, également parmi les femmes. Or le coût de fabrication des livres a sans doute été un obstacle majeur à leur acquisition par les moins fortunés et la constitution de bibliothèques, dont les plus importantes ont pu compter plus d'une centaine d'ouvrages, est restée le privilège de quelques lettrés, en particulier dans les centres d'études. Dans de telles conditions, les rabbins ont pu envisager le prêt et la location de livres avec prudence, en raison des risques de perte ou de dégradation, et les synagogues ont joué le rôle de bibliothèques publiques en mettant à disposition des membres de la communauté qui le souhaitaient les ouvrages qu'elles conservaient.

5. C. SiRAt, Du scribe au livre: les manuscrits hébreux au Moyen Âge, Paris, 1994 ; M. BeIT-ARIÉ, Hebrew Manuscripts of East and West Toward a Comparative Codicology, Londres, 1992 ; B. NARKIS, Hebrew Illuminated Manuscripts, Jérusalem, Keter Publishing House, 1960. 
Les relations étroites existant entre les communautés, aussi bien dans les mondes ashkénaze et sépharade, qu'entre le nord et le sud de l'Europe, ont permis la diffusion rapide des textes et la circulation des livres, ainsi que leur pérennité et leur survie dans les périodes de persécution ou d'exil. Malgré tout, l'impression de pénurie d'ouvrages est récurrente dans les milieux juifs tout au long du Moyen Âge et D. Lévy Willard tente de la nuancer, malgré l'absence de données quantitatives, par une approche de la destination des ouvrages, en fonction de leur contenu : il n'est pas exclu, ainsi, que les familles aient pu posséder un ou deux livres, au moins la Haggada, rituel des deux premiers soirs de la Pâque célébré, non pas à la synagogue, mais au sein de la maison familiale. Car, comme le remarque à plusieurs reprises D. Lévy Willard, le livre a un caractère «quasi sacré » (p. 59) dans le monde juif, objet fréquemment comparé à l'homme, et qui, comme ce dernier, est enterré au soir de sa vie. Le Sefer Hassidim, livre des piétistes allemands de la fin du XII et du début du XIII ${ }^{\mathrm{e}}$ siècle, recommande aussi, en cas d'incendie, certes de sauver d'abord les hommes, mais de mettre à l'abri, aussitôt après, leurs livres.

L'ampleur des thèmes abordés par D. Lévy Willard, dont chacun pourrait être l'objet d'une monographie, fait de cet ouvrage, malgré quelques imprécisions d'un chapitre à l'autre et la qualité inégale des vingt-quatre illustrations retenues, un précieux ouvrage de référence pour appréhender la culture des sociétés juives médiévales. 